\title{
Bipolar or Unipolar Hemiarthroplasty after Femoral Neck Fracture in the Geriatric Population
}

\author{
Egemen Ayhan ${ }^{1}$, Hayrettin Kesmezacar ${ }^{1}$, Özgür Karaman², Adem Şahin ${ }^{3}$, Nail Kır ${ }^{1}$ \\ ${ }^{1}$ Department of Orthopaedics and Traumatology, Istanbul University Cerrahpaşa School of Medicine, Istanbul, Turkey \\ ${ }^{2}$ Department of Orthopaedics and Traumatology, Fatih Sultan Mehmet Research and Training Hospital, Istanbul, Turkey \\ ${ }^{3}$ Department of Orthopaedics and Traumatology, Çorlu Public Hospital, Tekirdağ, Turkey
}

\begin{abstract}
Background: The choice of prosthesis in hemiarthroplasty is controversial for geriatric patients after femoral neck fracture. We hypothesised that selection criteria for unipolar or bipolar prostheses could be constructed based on factors affecting mortality.

Aims: The aims of this retrospective study were: (1) to determine the factors affecting mortality of femoral neck fracture patients $\geq 65$ years of age; (2) to compare patient mortality rates, radiological findings, and functional outcomes according to prosthesis type (unipolar or bipolar); and (3) to evaluate the persistence of inner bearing mobility of bipolar prostheses.
\end{abstract}

Study Design: Retrospective comparative study.

Methods: In total, 144 patients operated for hemiarthroplasty and aged $\geq 65$ were included. We classified the patients into either unipolar or bipolar prosthesis groups. To reveal factors that affected mortality, age, sex, delay in surgery, and American Society of Anesthesiologists score were obtained from folders. Barthel Daily Living, Harris hip, and acetabular erosion scores were calculated and bipolar head movement was analysed for live patients.

Results: One-year mortality was $31.94 \%$. Age $\geq 75(p=0.029)$, male sex $(p=0.048)$, and delay in surgery $\geq 6$ ( $p=0.004)$ were the patient characteristics that were related to increased mortality. There were no significant differences in sex, age, American Society of Anesthesiologists score, delay in surgery, mortality, or Barthel, Harris, acetabulum scores between the two groups. Twenty patients from each group were admitted for last follow-up. Bipolar head movement was preserved for $33.3 \%$ of patients. They were inactive patients with low Barthel and Harris scores.

Conclusion: Although bipolar head movement was preserved in inactive patients, we suppose that this conferred no advantage to these patients, who could hardly walk. In this study, male patients, those aged $\geq 75$ years, and those operated at $\geq 6$ days had an increased risk of mortality. Also, although not significant in multivariate analysis, high American Society of Anesthesiologists score ( $\geq 3$ ) was related to increased mortality. Considering that one of three patients died during the first postoperative year, we think that these patients should be operated as soon as possible, and expensive bipolar prostheses must be used selectively in regard to patient characteristics.

Key Words: Femoral neck fracture, mortality, hemiarthroplasty

Received: 08.02.2013 Accepted: 05.10.2013

\section{Introduction}

The geriatric population is the fastest growing worldwide, and femoral neck fractures have arisen as a major public health problem. Increased mortality is known to persist for several years postfracture (1), with a 1-year mortality rate of 14 to $36 \%(2,3)$. Surgery is the first choice of treatment for femoral neck fractures. Although some authors have reported better results with internal fixation (4), hemiarthroplasty is still accepted as the optimum treatment for displaced femoral neck fractures in most elderly patients (5). Total hip arthroplasty is an alternative for active patients with a long life expectancy and arthritic joints.

The choice of prosthesis in hemiarthroplasty is controversial. Some authors advocate the unipolar prosthesis, whereas others prefer the bipolar prosthesis (5-13). The theoretical advantage of the bipolar prosthesis is the motion at its inner bearing in addition to the prosthesis-acetabulum interface (14). This should decrease the amount of acetabular erosion, as evidenced radiologically, and reduce pain clinically. Nevertheless, studies have shown that the inner bearing loses mobility over time and that the bipolar prosthesis behaves similarly to the unipolar prosthesis $(15,16)$. Moreover, the two- to five-fold increased cost of the bipolar prosthesis compared with the unipolar prosthesis poses the question of whether it affects quality of life and functional results in elderly patients after fractures with high mortality rates.

We hypothesised that selection criteria for unipolar or bipolar prostheses could be constructed based on factors affecting mortality of patients with femoral neck fractures. Therefore, the aims of this retrospective study were: (1) to determine the factors affecting mortality of femoral neck fracture patients $\geq 65$ years of age; (2) to compare patient mortality rates, radiological findings, and functional outcomes according to prosthesis type (unipolar or bipolar); and (3) to evaluate the persistence of inner bearing mobility of bipolar prostheses. 


\section{Material and Methods}

This was a retrospective comparative study that received local ethics committee approval. Informed consent was obtained from all live patients. From 1 January 2001 until 1 January 2008, a total of 235 displaced femoral neck fracture patients aged 65 years and older were treated in our institute. Inclusion criteria were having been previously ambulatory and an at least 1-year postoperative follow-up if they survived. Patients with pathological fractures (12 patients), with insufficient or inconsistent preoperative data (17 patients), and those who were treated with internal fixation (28 patients) or total hip arthroplasty (32 patients) were excluded. One patient from the unipolar prosthesis group and one from the bipolar prosthesis group were excluded due to postoperative complications (dislocation). Finally, 144 patients were included in the study.

We checked postoperative radiographs and classified the patients into either the unipolar or bipolar prosthesis groups. The unipolar prosthesis group included the Thompson, Leinbach, and modular head unipolar prostheses. Age at admission, sex, trauma date, number of days until surgery, and the American Society of Anesthesiologists (ASA) physical status score were obtained from patients' computerised data, hospital charts, and folders. The ASA score was used by the anaesthesiologists to predict operative risk.

Patients' recent health status information was obtained by telephone interview. To reveal factors that affected mortality, the patients were grouped as either alive or dead. The postoperative survival period was assessed for the dead patients. Twenty patients from the bipolar prosthesis group and 20 patients from the unipolar prosthesis group agreed to undergo a last follow-up. For these 40 patients, informed consent was obtained, physical examinations were performed, and the Barthel daily living activity (17) and Harris hip (18) scores were calculated. For radiological evaluation of these patients, anterior-posterior pelvis radiographs (Siemens, Erlangen, Germany) were taken and acetabular erosion was determined using the method described by Phillips (19). In this method, the reference points are taken from the contralateral normal hip, and the precise postoperative location of the prosthetic femoral head is determined according to the lines drawn from these reference points as follows: in order to measure acetabular erosion, a horizontal line is drawn through the proximal limits of the obturator foramina and a parallel line through the upper margins of the femoral head of the contralateral hip. This locates the original superior margin of the prosthetic head. The original medial margin of the prosthetic head is determined similarly, by measuring the distance from the ilioischial line. The difference between the last position of the prosthetic femoral head and the postoperative location of the prosthetic femoral head is then measured. This is the amount of acetabular erosion (Figure 1). Finally, the acetabulum score is calculated by the following formula:

100 - (acetabular erosion amount / femoral head diameter) $X 100$

For the patients in the bipolar prosthesis group, additional radiographs of the hips were taken in abduction, adduction, internal rotation, and external rotation to analyse bipolar head movement. The mobility of the bipolar head was scored according to the system of Phillips. In this fluoroscopy scoring system for bipolar head motion, the classifications are as follows: Type A, all movement at inner metal/polyethylene surface until outer head/neck impingement; Type $B$, movement shared between outer metal/cartilage and inner metal/polyethylene surfaces; and Type C, all movement at outer metal/ cartilage surface (20).

\section{Statistical analysis}

For the statistical analysis NCSS (Number Cruncher Statistical System) 2007 \& the PASS (Power Analysis and Sample Size) 2008 Statistical Software (Utah, USA) program were used. The unadjusted $\chi^{2}$ test was used to evaluate differences between proportions. The unpaired Student's t-test was used to evaluate differences between means that with a normal distribution and the Mann-Whitney $U$ test was used to evaluate differences between medians. Continuity Correction Yates test was used for gender-related mortality analysis. To determine the association between potential predictors and mortality, the Enter Logistic Regression Analysis test was used. In this method, the cut-off values were taken as 75 for age and 6 days for delay in surgery. These cut-off points were determined according to receiver operating curve (ROC) analysis and sensitivity-specificity tests. The results were analysed in $95 \%$ confidence interval and a $p$ value of $<0.05$ was defined as significant in all tests. In power analysis, according to the delay in surgery parameter (delta was taken as 3 days and standard deviation was taken as 6 days), sample size was calculated to be at least 62 for $80 \%$ power and $\alpha=0.05$.

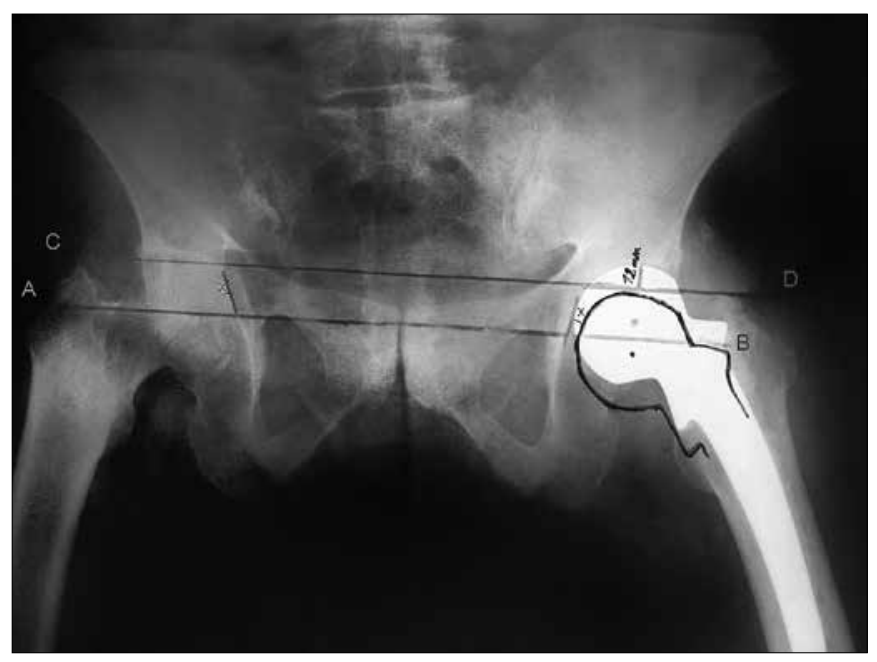

Figure 1. A 2-year postoperative anterior-posterior pelvis radiograph of a 76-year-old female patient operated with a unipolar prosthesis. The patients' Harris hip score was 83 and Barthel daily living activity score was 20 at last follow-up. In this example, the area of erosion measured $12 \mathrm{~mm}$ and the diameter of the femoral head measured 48 $\mathrm{mm}$; therefore, the acetabular score was 100 - (12/48) $X$ $100=75$ 
Table 1. Baseline characteristics of live and dead patients

\begin{tabular}{|c|c|c|c|c|}
\hline & Live $(n=62)$ & Dead (n=82) & p (univariate analysis) & p (multivariate analysis) \\
\hline \multicolumn{5}{|l|}{ Age } \\
\hline Mean (Years) & $76.53 \pm 7.15$ & $79.46 \pm 7.98$ & $0.024^{\star}$ & $0.029^{\star}$ \\
\hline \multicolumn{5}{|l|}{ Sex } \\
\hline Male & 15 (24.2\%) & 37 (45.1\%) & & \\
\hline Female & 47 (75.8\%) & 45 (54.9\%) & $0.016^{\star}$ & $0.048^{*}$ \\
\hline \multicolumn{5}{|l|}{ ASA } \\
\hline Mean & $2.61 \pm 0.66$ & $2.90 \pm 0.60$ & & \\
\hline Median & 3 & 3 & $0.020^{\star}$ & 0.538 \\
\hline \multicolumn{5}{|l|}{ Delay in Surgery } \\
\hline Mean (Days) & $9.58 \pm 11.02$ & $11.79 \pm 11.46$ & & \\
\hline Median (Days) & 5 & 8 & $0.024^{\star}$ & $0.004^{\star}$ \\
\hline
\end{tabular}

Table 2. Baseline characteristics of unipolar and bipolar prosthesis groups

\begin{tabular}{|c|c|c|c|}
\hline & Unipolar Prostheses $(n=81)$ & Bipolar Prostheses $(n=63)$ & $\mathbf{p}$ \\
\hline \multicolumn{4}{|l|}{ Age } \\
\hline Mean (Years) & $77.679 \pm 7.520$ & $78.873 \pm 8.039$ & 0.3607 \\
\hline \multicolumn{4}{|l|}{ Sex } \\
\hline Male & 35 (43.2\%) & $17(27 \%)$ & \\
\hline Female & $46(56.8 \%)$ & $46(73 \%)$ & 0.0548 \\
\hline \multicolumn{4}{|l|}{ ASA } \\
\hline Median & 3 & 3 & 0.1442 \\
\hline \multicolumn{4}{|l|}{ Delay in Surgery } \\
\hline Mean (Days) & $11.90 \pm 13.119$ & $9.93 \pm 9.181$ & 0.342 \\
\hline \multicolumn{4}{|l|}{ Mortality } \\
\hline 1 month & 14.81 & 12.69 & 0.8106 \\
\hline 6 months & 30.80 & 25.3 & 0.5771 \\
\hline 12 months & 35.8 & 26.9 & 0.2844 \\
\hline \multicolumn{4}{|l|}{ Follow-up Period } \\
\hline Mean (Months) & $32.52 \pm 27.145$ & $18.52 \pm 14.231$ & $<0.001^{\star}$ \\
\hline
\end{tabular}

\section{Results}

A total of 144 patients were included in this study. The mortality rates for 1 month and for the first 6 months were $13.88 \%$ and $28.47 \%$, respectively. The mortality rate declined following the first 6 months after surgery. One-year mortality was $31.94 \%$. There were 62 live patients and 82 patients were dead. The baseline characteristics of these two groups are summarised in Table 1 . We found that increasing age $(p=0.024)$, male sex $(p=0.016)$, high ASA score $(p=0.020)$, and delay in surgery $(p=0.024)$ were related to increased mortality in univariate analysis. We determined cut-off values as 75 for age and 6 days for delay in surgery according to ROC analysis and sensitivity-specificity tests. The risk factors (age $\geq 75$, male sex, ASA, and delay in surgery $\geq 6$ ) were analysed by the Enter Logistic Regression Analysis test and age $\geq 75(p=0.029)$, male sex $(p=0,048)$, and delay in surgery $\geq 6(p=0.004)$ were significant independent predictors of mortality in multivariate analysis.

The patients were separated into unipolar and bipolar prosthesis groups according to treatment type. There were $81(56.2 \%)$ patients in the unipolar prosthesis group and 63 $(43.8 \%)$ in the bipolar prosthesis group. The baseline characteristics of these two groups are summarised in Table 2. There were no significant differences in sex, age, ASA score, or delay in surgery between the two groups. However, for the last 3 years, because the bipolar prosthesis was the choice of treatment for almost all femoral neck fracture patients, the follow-up periods were different for the two groups $(p<0.001)$. Therefore, to determine the mortality rate according to treatment type, we analysed mortality rates during 1-, 6-, and 12-month follow-up periods. There were 
no significant differences in mortality rates between the two groups (Table 2).

Of the 62 live patients, 28 were in the unipolar prosthesis group and 34 were in the bipolar prosthesis group. Twenty unipolar prosthesis patients and 20 bipolar prosthesis patients were admitted for a last follow-up. In the unipolar prosthesis group, the mean age (73.938 \pm 6.298 years) and Harris hip (84.78 \pm 9.502$)$, Barthel (18.44 \pm 3.265$)$, and acetabulum scores $(86.66 \pm 11.208)$ were not significantly different than the mean age (76.917 \pm 7.845 years) and Harris hip (83.46 \pm 13.791$)$, Barthel $(18.25 \pm 2.701)$, or acetabulum scores $(90.15 \pm 7.615)$ of the bipolar prosthesis group $(p=0.2749, p=0.944, p=0.692$, $p=0.675$, respectively). The mean follow-up in the unipolar prosthesis group ( $58 \pm 22.042$ months) was significantly longer than that in the bipolar prosthesis group (18.33 \pm 6.14 months) $(p \leq 0.001)$.

While analysing bipolar head movements of the 20 bipolar prosthesis patients who were admitted for the last follow-up, we were not able to classify two patients because the positions were not adequately proportioned on the serial radiographs. For the remaining 18 patients, we observed type $A$ movement in three patients (Figure 2), type B movement in three patients, and type $\mathrm{C}$ movement in 12 patients (Figure 3 ). In other words, in a mean follow-up period of 23.5 months, we observed inner bearing movement (type $A$ and $B$ ) in six prostheses (33.3\%), while the remaining 12 prostheses $(66.6 \%)$ showed movement only at the outer articular surface (type C). We compared prostheses with inner bearing mobility (types $A$ and $B, n=6$ ) and immobility (type $C, n=12$ ). Between inner bearing mobile and immobile groups, there were no significant differences in mean age $(74.167 \pm 5.776,81.917 \pm 10.104$ years; $p=0.1035)$ or mean follow-up $(21.67 \pm 7.711,24.50 \pm 14.438$ months; $p=0.925)$. In terms of functional outcome, the mean Harris hip score was significantly $(p=0.028)$ lower in the mobile inner bearing prosthesis group $(66.68 \pm 14.153)$ than in the immobile group (82.84 \pm 12.920$)$. In addition, although not statistically significant $(p=0.175)$, the mean Barthel score of the mobile inner bearing group $(13.17 \pm 6.274)$ was lower than that of the immobile group (17.33 \pm 2.902$)$. However, regarding the radiological follow-up results, the mean acetabulum score in the mobile inner bearing group (96.0 13.742$)$ was significantly $(p=0.0233)$ higher than that in the immobile group (87.528 \pm 6.774$)$.

\section{Discussion}

Hemiarthroplasty is widely accepted as the optimum treatment for displaced femoral neck fractures in most elderly patients (5). However, the choice of prosthesis is controversial; some authors advocate the unipolar prosthesis, whereas others prefer the bipolar prosthesis (5-13). In this study, we hypothesised that selection criteria for unipolar or bipolar prosthesis could be constructed based on the factors affecting the mortality of patients with femoral neck fractures.

Several limitations in this study may have affected the results. First, the unipolar and bipolar prostheses were not classified according to their subtypes. Second, the study was a retrospective analysis and so is subject to the limitations of

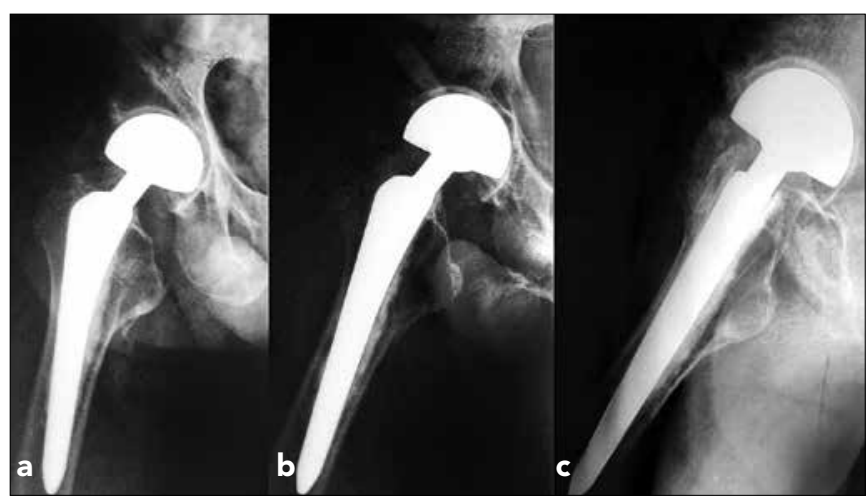

Figure 2. a-c. Twenty-four-month postoperative radiographs of a 76-year-old man. Radiograph taken in adduction position (a). Radiograph taken in abduction position (b). Radiograph taken in lateral position (c). All movement ensued at the inner bearing (metal/polyethylene) surface (Type A). Hip motion did not lead to alteration of the outer articular surface position

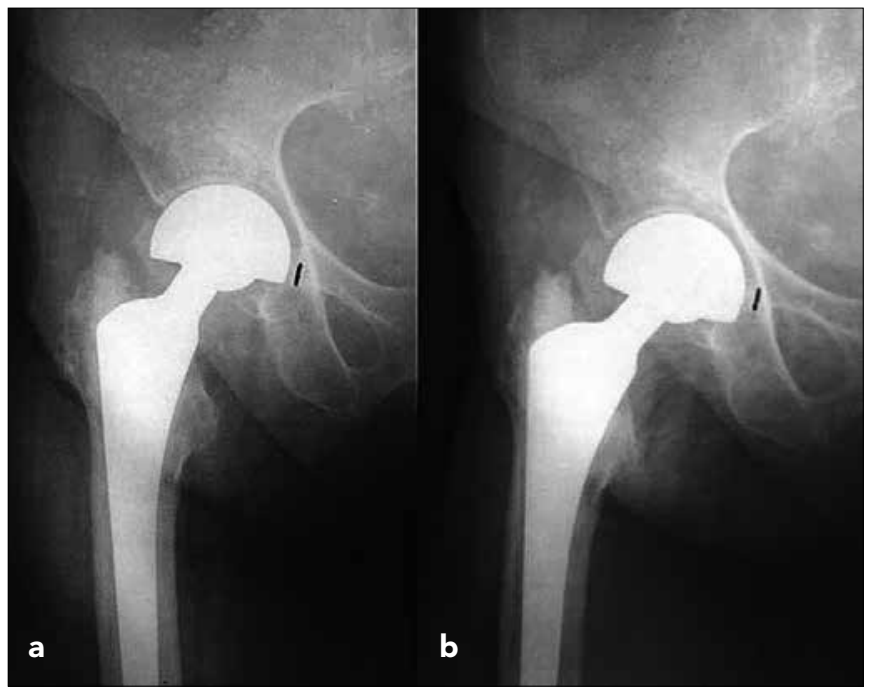

Figure 3. a, b. Twelve-month postoperative radiographs of a 68-year-old woman. Radiograph taken in adduction position (a). Radiograph taken in abduction position (b). All movement ensued at the outer metal/cartilage surface (Type C)

all retrospective studies. Finally, 22 patients were not willing to attend the last follow-up, and so these patients were not evaluated clinically or radiologically.

When all patients were considered, the mortality risk was increased after femoral neck fracture, especially during the first 6 months. Although the risk began to lessen after the sixth month, almost one-third (32\%) of the patients died in the first postoperative year. Many studies have reported that postfracture mortality is increased during the first year and then decreases gradually over time $(1,3)$.

In our study, high ASA score was related to increased mortality in univariate analysis, but in multivariate analysis, it was not a significant predictor of mortality. Also, we found that male sex was related to increased mortality in both univariate and multivariate analyses. Although controversial (2), it has 
been advocated that male sex is related to increased mortality, even when other potential confounders are controlled for (21). Moreover, the literature supports the current findings that increased age (2), high ASA score (22), and delayed surgery (23) are correlated with increased mortality (Table 1).

In this study, there were no significant differences in the mortality and complication rates between the unipolar and bipolar prosthesis groups. Although some contrary reports have been published $(5,12)$, most retrospective studies confirm our findings (6-8). Moreover, many recent prospective studies have also reported no significant difference between the outcomes of unipolar and bipolar hemiarthroplasty treatments after femoral neck fracture $(9,11,13)$. Finally, in a recent evidence-based Cochrane review, Parker et al. (24) reported no differences in mortality or complication rates between unipolar and bipolar hemiarthroplasty treatments.

Among the 40 patients that attended the last follow-up, the mean acetabulum score of the bipolar group patients was somewhat higher; nevertheless, the difference between the two groups was not significant. This might be due to the difference between the mean follow-up periods (unipolar group patients had a significantly longer mean follow-up period). In addition, this finding was not reflected in the daily living activities (Harris hip and Barthel scores). Similar clinical studies have shown that radiological erosion does not lead to clinical complaints $(9,10)$. Although significant acetabular erosion with unipolar prostheses has been reported (10), it was caused by the younger age and higher daily living activity of the affected patients $(6,9)$. In a recent Cochrane review, there was no difference in acetabular erosion between unipolar and bipolar prostheses (24). Unipolar prostheses seem likely to lead to more acetabular erosion during long-term followup, but how long the inner bearing surface motion of bipolar prostheses will continue is debatable $(15,16,25)$.

In our bipolar head analysis, there was no significant difference in the mean follow-up period between the mobile inner bearing (types $A$ and $B$, six patients) and immobile (type $C, 12$ patients) groups. In a mean follow-up period of 23.5 months, two-thirds of bipolar prostheses behaved like unipolar prostheses, moving only from the outer articular surfaces. In previous studies, a decrease in inner bearing motion over time was reported $(15,16)$. Verberne et al. (16) demonstrated cessation of inner bearing motion at the third postoperative month, and Chen et al. (15) reported similar findings at the second postoperative year. Polyethylene lubricant behaviour deterioration, foreign body reaction to the polyethylene debris, and wedge impaction of the metal head onto the polyethylene are the hypotheses for the loss of inner bearing motion (15, 16). On the other hand, Bochner et al. (25) reported maintenance of the inner bearing motion at the third postoperative year. However, in a prospective controlled study, Dalldorf et al. (26) compared acetabular cartilage biopsies obtained during hemiarthroplasty revision surgery with those from a control group. They reported that acetabular erosion was related to the length of time that the prosthesis was in place rather than to the type of prosthesis.

Theoretically, minimal radiological acetabular erosion is expected in patients with preserved bipolar motion. In our study, the mean acetabulum score was significantly higher in the six mobile inner bearing patients (types $A$ and $B$ ) than the 12 immobile inner bearing patients (type $C$ ). The theoretical advantage of bipolar motion was confirmed radiologically in these patients. However, this advantage was not reproduced in terms of functional outcome. The mean Harris score was significantly lower for types $A$ and $B$ patients than for type $C$ patients. We believe this dilemma to be related to the inactivity of the patients. Bipolar motion might be preserved due to the decreased loading of prostheses in less active patients. For an example, in Figure 2, that patient was suffering from hemiplegia, with a Harris hip score of 68.2 and a Barthel score of 13 . Bipolar motion was preserved probably due to the decreased daily living activity and decreased loading of the prosthetic hip in that patient. Confirming this, although not significant, the mean Barthel daily living activity score was also lower for types $A$ and $B$ patients (13.17) than for type C patients (17.33). Similarly, Tsukamoto et al. (27) demonstrated loss of inner bearing motion with increased loading (20 kg) of prostheses in their cadaver study. Drinker and Murray (6) reported that obvious inner bearing motion in the supine position was significantly reduced with loading on the extremity. Wedge impaction of the metal head onto the polyethylene with the loading hypothesis (15) also supports our theory.

In conclusion, although it is predicted that the unipolar prosthesis may lead to more acetabular erosion in the long term, how long the inner bearing surface movement of the bipolar prosthesis will continue is unclear. In active patients, probably due to repeated loading, the inner bearing surface movement of bipolar prostheses ceases. In our study, although the bipolar head movement was preserved in inactive patients, we suppose that this conferred no advantage to these patients, who could hardly walk. In this study, male patients, those aged $\geq 75$ years, and those operated at $\geq 6$ days had an increased risk of mortality. Also, although not significant in multivariate analysis, high ASA score $(\geq 3)$ was related to increased mortality. Considering that one of three patients died during the first postoperative year, we think that these patients should be operated as soon as possible, and expensive bipolar prostheses must be used selectively in regard to patient characteristics.

Ethics Committee Approval: Ethics committee approval was received for this study from the Istanbul University, Cerrahpaşa Medical Faculty Ethics Committee (Date: 08.04.2008).

Informed Consent: Informed consent was obtained from all live patients.

Peer-review: Externally peer-reviewed.

Author contributions: Concept - H.K., N.K., E.A.; Design - E.A., H.K.,Ö.K.; Supervision - H.K., N.K., E.A.; Resource - E.A., Ö.K., A.Ş.; Materials - E.A., Ö.K., A.Ş.; Data Collection\&/or Processing - E.A., Ö.K., A.Ş.; Analysis\&/or Interpretation - H.K., Ö.A., E.A.; Literature Search - E.A., Ö.K., A.Ş.; Writing - E.A., H.K.; Critical Reviews - H.K., N.K., E.A.

Conflict of Interest: No conflict of interest was declared by the authors.

Financial Disclosure: The authors declared that this study received no financial support. 


\section{References}

1. Vestergaard P, Rejnmark L, Mosekilde L. Has mortality after a hip fracture increased? J Am Geriatr Soc 2007;55:1720-6. [CrossRef]

2. Aharonoff GB, Koval KJ, Skovron ML, Zuckerman JD. Hip fractures in the elderly: predictors of one year mortality. J Orthop Trauma 1997;11:162-5. [CrossRef]

3. Kesmezacar H, Ayhan E, Unlu MC, Seker A, Karaca S. Predictors of mortality in elderly patients with an intertrochanteric or a femoral neck fracture. J Trauma 2010;68:153-8. [CrossRef]

4. Parker MJ. Internal fixation or arthroplasty for displaced subcapital fractures in the elderly? Injury 1992;23:521-4. [CrossRef]

5. Lu-Yao GL, Keller RB, Littenberg B, Wennberg JE. Outcomes after displaced fractures of the femoral neck:A meta-analysis of one hundred and six published reports. J Bone Joint Surg Am 1994;76:15-25.

6. Drinker H, Murray WR. The universal proximal femoral endoprosthesis. A short-term comparison with conventional hemiarthroplasty. J Bone Joint Surg Am 1979;61:1167-74.

7. Ong BC, Maurer SG, Aharonoff GB, Zuckerman JD, Koval KJ. Unipolar versus bipolar hemiarthroplasty:functional outcome after femoral neck fracture at a minimum of thirty-six months of follow-up. J Orthop Trauma 2002;16:317-22. [CrossRef]

8. Wathne RA, Koval KJ, Aharonoff GB, Zuckerman JD, Jones DA. Modular unipolar versus bipolar prosthesis:a prospective evaluation of functional outcome after femoral neck fracture. J Orthop Trauma 1995;9:298-302. [CrossRef]

9. Calder SJ, Anderson GH, Jagger C, Harper WM, Gregg PJ. Unipolar or bipolar prosthesis for displaced intracapsular hip fracture in octogenarians:a randomised prospective study. J Bone Joint Surg Br 1996;78:391-4.

10. Wetherell RG, Hinves BL. The Hastings bipolar hemiarthroplasty for subcapital fractures of the femoral neck. J Bone Joint Surg Br 1990;72:788-93

11. Raia FJ, Chapman CB, Herrera MF, Schweppe MW, Michelsen $\mathrm{CB}$, Rosenwasser MP. Unipolar or bipolar hemiarthroplasty for femoral neck fractures in the elderly? Clin Orthop Relat Res 2003;(414):259-65. [CrossRef]

12. LaBelle LW, Colwill JC, Swanson AB. Bateman bipolar hip arthroplasty for femoral neck fractures. A five- to ten-year follow-up study. Clin Orthop Relat Res 1990;(251):20-5.

13. Davison JN, Calder SJ, Anderson GH, Ward G, Jagger C, Harper $W M$, et al. Treatment for displaced intracapsular fracture of the proximal femur. A prospective, randomised trial in patients aged 65 to 79 years. J Bone Joint Surg Br 2001;83:206-12. [CrossRef]

14. Bateman JE. The classic: single-assembly total hip prosthesispreliminary report. 1974. Clin Orthop Relat Res 2005;441:16-8. [CrossRef]

15. Chen SC, Badrinath K, Pell LH, Mitchell K. The movements of the components of the Hastings bipolar prosthesis. A radiographic study in 65 patients. J Bone Joint Surg Br 1989;71:186-8.

16. Verberne $\mathrm{GH}$. A femoral head prosthesis with a built-in joint. A radiological study of the movements of the two components. J Bone Joint Surg Br 1983;65:544-7.

17. Mahoney FI, Barthel DW. Functional evaluation: the Barthel Index. Md State Med J 1965;14:61-5.

18. Mahomed NN, Arndt DC, McGrory BJ, Harris WH. The Harris hip score: comparison of patient self-report with surgeon assessment. J Arthroplasty 2001;16:575-80 [CrossRef]

19. Phillips TW. Thompson hemiarthroplasty and acetabular erosion. J Bone Joint Surg (Am), 1989;71-A:913-917.

20. Phillips TW. The Bateman bipolar femoral head replacement. A fluoroscopic study of movement over a four-year period. J Bone Joint Surg Am 1989;71:913-7.

21. Magaziner J, Simonsick EM, Kashner TM, Hebel JR, Kenzora JE. Survival experience of aged hip fracture patients. Am J Public Health 1989;79:274-8. [CrossRef]

22. Michel JP, Klopfenstein C, Hoffmeyer P, Stern R, Grab B. Hip fracture surgery: is the pre-operative American Society of Anesthesiologists (ASA) score a predictor of functional outcome? Aging Clin Exp Res 2002;14:389-94. [CrossRef]

23. Sircar P, Godkar D, Mahgerefteh S, Chambers K, Niranjan S, Cucco R. Morbidity and mortality among patients with hip fractures surgically repaired within and after 48 hours. Am J Ther 2007;14:508-13. [CrossRef]

24. Parker MJ, Gurusamy K. Arthroplasties (with and without bone cement) for proximal femoral fractures in adults. Cochrane Database Syst Rev 2006;19;3:CD001706.

25. Bochner RM, Pellicci PM, Lyden JP. Bipolar hemiarthroplasty for fracture of the femoral neck. Clinical review with special emphasis on prosthetic motion. J Bone Joint Surg Am 1988;70:1001-10.

26. Dalldorf PG, Banas MP, Hicks DG, Pellegrini VD Jr. Rate of degeneration of human acetabular cartilage after hemiarthroplasty. J Bone Joint Surg Am 1995;77:877-82.

27. Tsukamoto Y, Mabuchi K, Futami T, Kubotera D. Motion of the bipolar hip prosthesis components. Acta Orthop Scand 1992;63:648-52. [CrossRef] 